\title{
Listening for the hiss: lo-fi liner notes as curatorial practices
}

\author{
ALEXANDRA SUPPER \\ Maastricht University, Department of Technology and Society Studies, Maastricht, the Netherlands \\ E-mail: a.supper@maastrichtuniversity.nl
}

\begin{abstract}
Lo-fi music is commonly associated with a recording aesthetic marked by an avoidance of state-ofthe-art technologies and an inclusion of technical flaws, such as tape hiss and static. However, I argue that lo-fi music is not defined merely by the presence of such imperfections, but by a discourse which deliberately draws attention to them. Album liner notes play an important role in this discourse, as they can function as curatorial practices, through which lo-fi artists give an appropriate frame of reference to their recordings. By highlighting the 'honest' character of the recordings, the intimate recording spaces, the materiality of the equipment and its ambiguous character as machinel instrument/performer, they invite listeners to adopt a genre-adequate mode of listening. Rather than listening past hiss and other recording artefacts as undesirable qualities, listeners are asked to listen for these qualities as an essential element of not just the recordings, but the music itself.
\end{abstract}

\section{Introduction}

'Recorded by Justin Vernon in the hunting cabin, Northwest Wisconsin.' This short statement in the liner notes of Bon Iver's indie folk album For Emma, Forever Ago describes an important element of the album's success: '[The recordings made in the hunting cabin] were supposed to be demos, but they caught fire when he posted them online; the subsequent album went on to sell more than 300,000 copies. The record's backstory has become central to its mythology - part Into the Wild, part Basement Tapes, part Walden, part Unabomber' (Eells 2011). The curious circumstances surrounding the recording have been reiterated in just about every Bon Iver interview and album review, but in this article, it is the short, matter-of-fact statement in the album's liner notes that I want to focus on. Liner notes such as these, I argue, help to draw the listener's attention to the deliberately lo-fi quality of the music, to certain flaws in the recordings that might otherwise go unnoticed or be interpreted as accidents rather than aesthetic strategies. In doing so, the liner notes invite particular modes of listening that are appropriate to lo-fi music. In other words, they are used by artists as a means of staging the recordings in such a way that they are seen as part of the universe of lo-fi; the artists thus act as curators who position their music in a certain frame of reference.

'Lo-fi' music is generally defined in opposition to hi-fi, state-of-the-art recording equipment, and is characterised by the deliberate presence of a 'low signal-to-noise ratio' (Kromhout 2012) and a 'rough and ragged sound quality, often failing to 
mask hum, static, tape hiss, and other noises endemic to the very process of recording' (Grajeda 2003, p. 357). The category of lo-fi has come to encompass not only an approach to recording (which will be the focus of this paper), but also to performance, such as 'the use of simplistic forms, odd instruments, (...) and amateur performances' (Dolan 2010, p. 464), as well as 'amateurish playing (often on minimal instrumentation), off-key singing, and a certain casualness in delivery' (Grajeda 2003, p. 357). The term is most commonly associated with indie and alternative music scenes starting in the 1990s, spearheaded by bands such as Sebadoh and Guided by Voices (Grajeda 2003). Since then, 'lo-fi sound' has become an important element of the aesthetics of indie pop (Dolan 2010), indie rock (Hibbett 2005) and new folk (Encarnacao 2013).

With its penchant for 'old electronics' (Dolan 2010, p. 464) and avoidance of 'advanced technology' (Grajeda 2003, p. 359), lo-fi music provides a counter-point to accounts of the historical development of music technology that are written in terms of how new technologies have changed music production and consumption (Pinch and Bijsterveld 2004) and in terms of the goal of 'perfecting sound forever' (Milner 2009). Lo-fi thus forms part of a wider context that has been labelled 'technostalgia', characterised by a revival of vintage gear (Pinch and Reinecke 2009) and analogue media such as vinyl and cassettes (Campopiano 2014; Eley 2011). It is linked also to the aesthetics of imperfection and malfunction common in some electronic and experimental music scenes (Demers 2010; Kelly 2009).

An important theme in existing scholarship on lo-fi music concerns the construction of authenticity (Dolan 2010; Grajeda 2003; Kromhout 2012). Emily Dolan, for instance, argues that a lo-fi sound

draws attention to the mediating technologies at work. Just as scratches on an old record or the hiss of cassette tape break the illusion of an unmediated experience with the music, so too the outdated instruments and amateur playing draw attention to the technologies behind the production. Here the 'honesty' of this music does not arise from the illusion of unmediated communication (which lurks behind so many 'unplugged' concerts), but rather from openly emphasising the process of mediation. (Dolan 2010, p. 464)

Although I agree with Dolan about lo-fi's ability to make visible the process of mediation involved in sound recording, I disagree that this ability is a direct result of the quality of the recording. In fact, I start my analysis from the assumption that a recording cannot be considered 'hi-fi' or 'lo-fi' in and of itself, by virtue of the flaws, distortions or noises it may or may not exhibit; rather, it is the context surrounding the recording and the conditions under which it is listened to that make it one or the other. Underpinning this assumption is a notion of 'fidelity' as socially constructed and subject to historical change (Barry 2015; Devine 2013; Sterne 2003), especially Jonathan Sterne's formulation of fidelity as 'a set of social and sonic relations in which participants could have faith' (Sterne 2003, p. 274). Consequently, whether a recording is considered lo-fi is not so much a question of whether it exhibits hallmark features such as a reduced frequency range, static or tape hiss, nor even whether it does so as a matter of deliberate artistic choice (Kromhout 2012); rather, it becomes a question of whether these features are perceived as relevant qualities by listeners as well as performers. It thus relies upon the employment of particular listening modes that are appropriate to the genre of lo-fi music.

In this article, I explore how such listening modes are cultivated in six steps. I begin by outlining the constructivist perspective upon fidelity and listening modes 
that underpins my argument. Subsequently, I explain the theoretical and methodological reasoning supporting my focus on liner notes. In four empirical sections, I then identify four strategies of drawing attention to the lo-fi-ness of the albums they accompany: invocations of honesty and authenticity; highlighting of the intimacy of recording spaces; emphasis on the equipment's materiality; and the raising of questions about its ambiguous character as machine, instrument or performer.

\section{High, low and in between: ${ }^{1}$ listening for/against fidelity and transparency}

Much of the history of sound recording has been written in terms of a search for everincreasing fidelity, or improved accuracy in reproducing an original source, usually a live performance. ${ }^{2}$ Closely related to this notion is the promise of transparency: to 'faithfully' reproduce a sound, the recording technology should not leave any audible traces of the recording process.

Some critics have questioned the relevance of fidelity and transparency in the context of popular and rock music, where recordings are rarely based on one-take live performances and are much more likely to form the listener's reference point for a live performance than vice versa (Gracyk 1996, p. 43; Morton 2000, p. 15). Still, it is widely accepted that any newly introduced recording technology would have to match or improve upon the fidelity and transparency afforded by its predecessors, as a system 'that would restrict recording to a more limited range of frequencies, or inject a higher level of noise or distortion (...) would be seen as degradation, not improvement' (Morton 2000, p. 47).

Nonetheless, the history of sound technology should not be regarded as one of linear progress towards a stationary target - for while all major new recording technologies promised improved fidelity, in practice this lofty ideal had to be balanced with other, often more pragmatic, concerns (Devine 2013; Sterne 2006). In fact, what was meant by 'fidelity' has changed over time: 'after 1878, every age has its own perfect fidelity' (Sterne 2003, p. 222) and competing definitions of fidelity may coexist, as historian Marsha Siefert (1995) shows in her analysis of the competition between phonograph and gramophone. Already in the late 19th century, when even the best recordings were 'limited in volume, compressed in tonal range, and very scratchy' (Sterne 2003, p. 258), phonographs were described as providing perfectly accurate reproductions - which was possible because fidelity is not a purely technical quality, but rather one that depends on social as well as on sonic relations (Sterne 2003, p. 274): 'The point was not to produce a perfectly silent apparatus (...).

1 The section headings in this paper, in order of appearance, are taken from the following releases, which will not be repeated in the discography, as it is limited to a listing of empirical sources:

(1) Townes van Zandt, 'High, low and in between', High, Low and In Between. Poppy, PYS 5700. 1972.

(2) Travis, 'Writing to reach you', The Man Who. Independiente, ISOM9CD. 1999.

(3) Silver Jews, 'We are real', American Water. Domino, WIGCC56. 1998.

(4) Bob Dylan, 'The ballad of Frankie Lee and Judas Priest', John Wesley Harding. Columbia, CS 9604. 1967.

(5) The Mountain Goats, 'The last limits of bhakti', Isopanisad Radio Hour. Yo-Yo, Yoyo LP-15. 2000.

(6) John Vanderslice, 'Me and my 424', The Life and Death of an American Fourtracker. Barsuk, bark24, 2002.

2 The dominance of the discourse on fidelity in histories of sound reproduction has recently been pointed out and questioned by Kyle Devine (2013), who argues that a more heterogeneous picture of the history of sound reproduction becomes possible when focusing on the notion of loudness. 
Rather, it was to produce an apparatus that listeners could pretend was silent' (Sterne 2003, p. 259f.). ${ }^{3}$

In order to create the conditions in which participants 'could have faith' in recordings, listeners were encouraged to disregard background sounds such as hissing and grinding noises; in other words, the maintenance of fidelity relied upon particular listening modes. In talking about listening modes, I draw upon a long tradition of work in sound studies, media studies, musicology and related fields of distinguishing between different modes of listening (Supper and Bijsterveld 2015), especially the work of music theorist Ola Stockfelt (1997), who argues - against hierarchical categorisations such as those of Theodor Adorno (1976 [1962]), who outspokenly preferred some modes of listening over others - that different modes of listening are appropriate for and demanded by different musical genres. According to Stockfelt, adopting an adequate mode means listening 'for what is relevant to the genre' (Stockfelt 1997, p. 137).

Without explicitly drawing upon Stockfelt, a number of scholars have started to explore what genre-appropriate modes of listening might mean in specific genres. In exploring the aesthetics of experimental electronic music, Joanna Demers introduces the category of 'aesthetic listening', which - unlike modes of listening common in traditional Western art music - 'heeds intermittent moments of a work without searching for a trajectory that unites such moments' (Demers 2010, p. 151) and does not require blocking out extra-musical sounds. Based on her fieldwork in the Tokyo avant-garde musical scene of onkyo, ethnomusicologist Lorraine Plourde discusses the 'disciplined listening' demanded of listeners in this radically minimalist improvisatory genre, which is distinguished by 'its seemingly utter lack of any discernible musical structure' and is 'often performed at barely audible levels' (Plourde 2008, p. 270). Audience members at onkyo concerts frame their listening practices in terms of concentration, endurance, patience and discipline. Such a disciplined mode of listening does not come naturally to the listeners, but is enforced through spatial and material conditions as well as through texts:

Listeners in this community are dependent on the constant production and circulation of such knowledge - in the form of public talks and performances, pamphlets and handouts at concerts, special issue journals and magazines, musicians' blogs and everyday conversation - in order to achieve so-called proper listening and comprehension. (Plourde 2008, p. 271)

Onkyo is not the only musical genre which rests upon the circulation of knowledge to invite or stimulate appropriate modes of listening. The introduction of new sound technologies, too, was often accompanied by explicit instructions for how to listen. When stereo sound was introduced, for instance, a great number of booklets and demonstration records were produced to dispense instructions for listening to the new devices (Théberge et al. 2015, especially the chapters by Anderson, Grajeda and Tee).

Even earlier, the introduction of the phonograph was accompanied by efforts to stimulate listeners' faith in their fidelity, for instance through so-called 'tone tests', in which early 20th century audiences were invited to guess whether they were

${ }^{3}$ One advantage of such a constructivist definition of fidelity and transparency is that it is not affected by critiques, such as those by Morton (2000) and Gracyk (1996) quoted above, of becoming obsolete when recordings do not aspire to reproduce one-take live performances. 
listening to a live singer or a phonograph. To contemporary listeners, it is hard to imagine that anyone might have been fooled; however, that may not have been the point, argues historian Emily Thompson (1995): regardless of whether listeners could differentiate between live performance and recording, the tone tests helped them "to transform their conception of what constituted "real music" to include phonographic reproductions' (Thompson 1995, p. 160).

Perfect fidelity is thus not a purely technical problem; it relies on particular listening practices, which are stimulated through techniques of staging the recordings. Marc Perlman's (2004) ethnography of audiophile culture gives a clue about the listening modes commonly adopted by listeners who cherish perfect fidelity. Perlman found that many audiophiles prefer vinyl over digital technologies, even if it features a significant amount of surface noise and hiss - qualities that, according to one audiophile interviewed by Perlman, 'after a minute you listen past' (Perlman 2004, p. 787). This approach is characteristic for the audiophile community, but different from how an archetypal lo-fi listener might describe listening to the same recording: while the appropriate listening mode for an audiophile is to listen past the hiss and noise, a lo-fi listener would instead listen for the same qualities. Just as high fidelity requires certain listening modes that allow listeners to have faith in the idea of an unmediated recording, lo-fi builds upon a listening mode that shatters this faith. Such a mode of listening - which I refer to as 'listening for the hiss', with 'hiss' serving as a

pithy stand-in for the range of qualities typically associated with lo-fi music requires cultivation.

\section{Writing to reach you: curatorial practices in liner notes}

Thus, I want to explore how listeners are invited or instructed by artists or record labels to pay attention to those qualities of the recordings that make them lo-fi. To do so, I will analyse texts that come packaged together with the music, especially album titles and liner notes (as well as their digital counterparts on the internet, such as descriptions accompanying recordings on the website Bandcamp.com). Focusing on these materials is not just a methodological choice, but also forms a substantial part of my argument about how particular modes of listening are instilled in listeners by giving the appropriate staging and framing to the music recordings themselves.

Liner notes have often been mined for quotes in passing in popular music scholarship. Schilt (2003), for instance, uses them as a source of information about the Riot Grrrl scene. Similarly, Bennett (2002) quotes liner notes in his exploration of the discursive construction of a 'Canterbury Sound'; yet while he explicitly reflects on the role of digital media in this discourse, he does not do the same for liner notes. However, some recent articles make more sustained use of liner notes as research resources, also reflecting on their use by artists as a medium through which to communicate with listeners. For instance, liner notes feature prominently in Matula's (2007) and Wright's (2013) analyses of the rhetoric and aesthetic of, respectively, post-punk band the Make-Up and funk group Funkadelic.

Perhaps the most systematic contribution towards analysing liner notes as a literary genre has been made by Biron (2011), who argues that they should be understood as instances of polytextuality. After giving some glimpses of the history of the genre, he distinguishes five types: literary, tangential, expository, propagandist and 
retrospective liner notes. While the studies by Matula (2007) and Wright (2013) mentioned above would fall under the banner of 'propagandist' liner notes, a recent article by Bottomley (2016) focuses - without referring to Biron - on 'retrospective' ones. Focusing on reissue practices in rock music, Bottomley (2016) argues that 'paratexts like liner notes aim to convince audiences that old recordings are aesthetically and historically significant and thus worth revisiting' (p. 163). In doing so, they simultaneously 'present (decode) a vision' of the past by explaining the music's original context, and also 'inscribe (recode) new meaning to the text, offering contemporary audiences particular ways to listen to the recordings' (Bottomley 2016, p. 164).

It might be tempting to assume that such practices of directing listener attention are limited to expository and retrospective liner notes, which have the most explicit didactic aims. The liner notes analysed in my paper, however, span the different genres distinguished by Biron (2011). Some of them drily state the circumstances of recording; others go off on literary tangents; others again stray into quasi-ideological musings - but what they share is their embedding of the releases they accompany into a context which draws attention to the lo-fi character of recordings. Doing so may, or may not, involve explicit invocations of the listener or instructions for how to listen. In reference to work in museum studies about how curatorial choices about the staging of particular objects provide visitors with a frame of reference for making sense of them (Leonard 2014), it is useful to think of them as curatorial practices employed by the artists or labels.

My point here is not that listeners would be unable to identify recordings as lo-fi without the help of liner notes; in the early 21st century, when digital recording technology has made (semi-)professional recordings cheaper and more accessible than ever before, listeners may be quite likely, even without prodding, to interpret a recording that contains a reduced frequency range or a significant amount of hiss as the result of artistic choice rather than technical or financial necessity. Neither can they guarantee that listeners will identify a recording as lo-fi; after all, listeners may not even have access to the liner notes if they listen to the album digitally. Even if they do hold the physical release in their hands while listening, they may not read the notes, or they may read them but lack the necessary background knowledge to place them as in a discourse of lo-fi aesthetics.

While liner notes are thus neither necessary nor sufficient conditions to ensure that recordings will be identified as requiring a lo-fi mode of listening by its listeners, they do form part of a wider set of curatorial practices through which artists help their listeners make sense of the lo-fi nature of their music. Just as hi-fidelity is a social construct relying upon particular modes of listening, so is lo-fidelity, and just as tone-tests and instructional booklets helped to cultivate hi-fidelity listening practices, liner notes help to cultivate lo-fidelity listening practices.

Of course, not all lo-fi recordings come with programmatic titles or liner notes to provide such a curatorial voice. For the purposes of my argument, it is irrelevant what percentage of them do - and in the absence of a definitive database of lo-fi releases, determining such a percentage would be a lost cause anyway. In collecting the material for this article, I looked through the album sleeves of releases that I suspected could be considered lo-fi (physically, in my own and friends' music collections, and digitally on Discogs.com), and noted down anything I could find that hinted at lo-fi listening modes. If I couldn't find anything in one album, I simply moved on to the next - without worrying whether this means that the album in question is not a real lo-fi album, or that it is a lo-fi album which contains no specific 
efforts to stimulate a lo-fi listening mode. After all, it is not my goal to come up with an essential definition of what counts as lo-fi recordings, but rather to demonstrate that liner notes can display curatorial practices that help listeners place recordings within the frame of reference of 'lo-fi', and analyse how they accomplish this. The mere fact that so many albums explicitly mention the lo-fi nature of their recordings is enough to suggest that a significant number of recording artists do find it necessary or desirable to stage their recordings in this manner. In the following sections, I will analyse several tropes that emerge from the efforts of artists to invite genreappropriate modes of listening in album liner notes and other texts that accompany the musical releases.

\section{We are real: authenticity and spontaneity}

A recurring theme in the existing literature on lo-fi music is the construction of authenticity in this genre, which 'eschews high production values in favour of nothing other than the "truth"' (Dolan 2010, p. 457; also see Kromhout 2012). ${ }^{4}$ Matula (2007) discusses such invocations of authenticity in the liner notes of the MakeUp's debut Destination: Love; Live! At Rice, in which the band declares their abstinence from 'the technical achievements used in the recording industry', which would 'alter the authenticity of the album'.

Indeed, a number of lo-fi releases explicitly suggest that the reliance on lo-fi recording techniques is primarily a matter of authenticity. A very outspoken example of this is tucked away on a small piece of paper in the breast pocket of the handmade packaging, made to resemble a sweater, of Colin Clary's Sweater Weather or Not, These Are the Songs I Got. The liner notes not only contain instructions for how to listen to the album ('like each song was written for you or for one of your friends'), but also include the following appeal to authenticity:

Any imperfections are the result of Colin's willingness to allow for imperfections within the context of an authentic home-recorded revolutionary master plan and should only serve to remind you that actual human beings just like you played the music on this album.

Similarly, the aptly titled compilation of covers Low Fidelity: Songs by Request Vol. 1 by Rob Snarski is accompanied by the following description on the website Bandcamp. com, where it is available for streaming and download:

I've always had a penchant for 4-track demos and lo-fi home recordings especially back in the day of tape. To me they've held a charm and honesty where the flaws become the strengths; there's usually a more relaxed vocal delivery, an unbalanced mix and some awkward arrangements, which for whatever reason sound sweet to my ears. ${ }^{5}$

To achieve this honesty, Snarski recorded the songs 'at home - in the kitchen, office and bedroom', albeit on an iPhone rather than a 4-track recorder. It appears that

${ }^{4}$ Of course, constructions of authenticity have also been examined in relation to a great variety of other musical genres, including country (Peterson 1997), hip-hop (Solomon 2005) and straight-edge (Williams 2006).

5 From http://robsnarski.bandcamp.com/album/low-fidelity-songs-by-request-volume-1 (accessed 31 July 2015). 
Snarski is not alone in considering home recordings as especially honest. The liner notes to Paul Westerberg's 2002 album Stereo, for instance, state:

What you have here are songs written and recorded at home over a two-year period that followed a much longer period of performing, traveling, and explaining. Cut mostly live in the middle of the night, no effort was made to fix what some may deem as mistakes: tape running out, fluffed lyrics, flat notes, extraneous noises, etc. Many were written (or born if you will) as the tape rolled.

Unprofessional? Perhaps. Real? Unquestionably.

Incidentally, Stereo is the more polished half of a double album; it comes packaged together with the album Mono, released under the moniker of Grandpaboy, which is described in the liner notes as 'rock ' $n$ ' roll recorded poorly, played in a hurry, with sweaty hands and unsure reason'.

The British lo-fi band Beatnik Filmstars explicitly point out the lo-fi nature of their music in the subtitle of their 2007 album Shenaniganism (Tape Hiss $\mathcal{E}$ Other Imperfections), which was released on their own record label with the similarly programmatic name of 'The International Lo-Fi Underground'. In case these clues still left the listeners in doubt about their intentions, the liner notes explain the recording circumstances: 'Recorded in houses in Bristol England. No studios! No computers! This LP was written and recorded in 2 weeks.'

Beatnik Filmstars' proclamation that 'no computers!' were used in recording the album contains an interesting appeal to authenticity, as this might be read as reassurance that all the 'imperfections' on the album are in fact true artefacts of the recording process, rather than affectations that were added after the fact. After all, adding hiss or distortion to existing, often digital, recordings is a common practice, for instance with the help of software such as the 'iZotope Vinyl' plug-in for the ProTools digital recording software, which touts itself as 'the ultimate lo-fi weapon' (Campopiano 2014, p. 76). However, tools like these are contested, as some regard them as inauthentic or tacky - and certainly their usage generally appears to be elided in liner notes where it does take place. The existence of digital tools that simulate the sound of analogue equipment may well have played a role in the Beatnik Filmstars' decision to distance themselves from the use of computers.

A juxtaposition of the liner notes by Paul Westerberg and Beatnik Filmstars reveals some interesting similarities and differences that also resound in other lo-fi releases. First of all, both texts refer to the presence of mistakes: 'what some may deem as mistakes', as Paul Westerberg calls them, or 'imperfections', as they are referred to by Beatnik Filmstars, who had already reassured their listeners that 'Buzz, Clicks And Hums Are OK. CD Is Not Faulty!' on their previous album In Great Shape. In both cases, specific examples are referenced; so not only do the performers not gloss over the fact that mistakes are present, but they help the listeners to identify what these mistakes are. This might be particularly significant for the act of tape running out, mentioned by Westerberg, as this is not actually audible on the recordings themselves: the recording simply ends mid-note. Without the heads-up from Westerberg, listeners unfamiliar with the process of analogue recording might not be able to interpret the reason for and significance of this ending.

Both albums emphasise the temporality and spontaneity of the recordings, albeit in different ways. While the Beatnik Filmstars' album is said to have been written and recorded entirely in the time-span of two weeks, Paul Westerberg admits to a much longer gestation period. At the same time, he also stresses the spontaneous 
nature of the recordings, which were made in the middle of the night, in some cases while the songs were being written. This emphasis on spontaneity as a signifier of authenticity is a recurring feature in lo-fi music. To name but one additional example, it features heavily in the liner notes of Norfolk \& Western's Winter Farewell, which highlight the transitory character of the recordings. Norfolk \& Western singersongwriter Adam Selzer runs the Type Foundry recording studio in Portland, which moved locations during the making of the album; consequently, some songs were recorded in the studio's first location, others in the second, and others again in Selzer's apartment, which the liner notes refer to as the 'interim'. Indeed, the precise location of each track's recording is painstakingly noted in the sleeve, as is the spontaneous nature of many of those recordings. For instance, one track was 'recorded at the interim, mostly in the entrance walk-in for the illustrious acoustics', while others were 'spontaneously written and recorded at the first. A few sounds added at the second' or recorded 'spontaneously while waiting for Rachel'.

\section{It's not a house, it's a home: site-specificity and intimacy}

These liner notes by Norfolk \& Western also serve as a good example of another trope that appears in many lo-fi releases: that of site-specificity. This aspect has been highlighted by Melle Kromhout (2012), who argues that lo-fi music is characterised by an avoidance of professional studios, which are associated with anonymous, interchangeable non-places. Through a strategy of site-specificity, in which the performance is grounded 'in an identifiable time and space' (Kromhout 2012), lo-fi musicians seek to infuse their recordings with authenticity. ${ }^{6}$

Kromhout raises an important point about the role of space, but remains unspecific about the kinds of places in which these 'site-specific' recordings usually take place: surprisingly, considering how closely lo-fi is associated with 'home-recording' (Grajeda 2003; Encarnacao 2013), the term 'home' does not appear in Kromhout's essay. A study of the liner notes of lo-fi releases makes it clear that the specific sites which are mentioned as recording locations are usually places that have associations with intimacy and homeliness. ${ }^{7}$ This homeliness is nicely captured, for instance, in the mixed metaphors of music and cooking contained in the liner notes to Kevin Tihista's Home Demons Vol. 1, which state that all songs were 'performed, recorded, produced, mixed, baked, eaten by Kevin Tihista'.

In fact, 'home' is the quintessential site of lo-fi recordings and has lent its name to several lo-fi releases besides Tihista's, including Adem's Homesongs and Peter Broderick's Home. While Adem's liner notes make clear that the album was recorded

6 The fact that the Norfolk \& Western album was studio-recorded does not make it an exception to the trend discussed by Kromhout, as the liner notes go to great length to infuse the Type Foundry studio with a geographical identity, specifying not only its location in Portland, but also the specific part of the city it is based in: the first studio in the Southeast, the second in the North.

7 Tony Grajeda (2003) has observed that many of these spaces are traditionally associated with women, and has used it as an argument to interpret lo-fi as a 'feminization of rock'. In the light of the fact that the artists he (and, it seems, every other commentator writing about lo-fi music, including myself) discusses are almost exclusively male, this seems like a somewhat oversimplified interpretation of the gender dimension of lo-fi - it might be more appropriate to discuss it as a construction of alternative masculinities. However, since liner notes are not the most suitable source of information regarding gender identities, a further exploration of this topic is beyond the scope of this paper. 
at this own home, Peter Broderick acknowledges 'the kind souls who allowed me their space to record and sleep in as I made this album (...). Thank you for giving me a home.'

Other albums that specify having been recorded 'at home' include The Creek Drank the Cradle by Iron \& Wine, The Proud Graduates by Spokane, and Reservations by Sodastream ('at home and other quiet places'). Sufjan Steven's Michigan was not recorded 'at home', but does mention the houses and apartments of a number of people as recording locations, including his own. Bulk by John Logan specifies the dates and places of recordings for each of its 42 tracks, usually identified by street name, including photos of three suburban-looking residential houses that featured prominently. These Things You Do At Four A.M. by Beltline and The Static vs. The Strings Vol 1 by Centro-Matic include similarly detailed song-by-song explanations, but without pictures (though Centro-Matic do include some visual information about drummer Matt Pence's 'powder blue two-story house' in Bernard Street, Denton). Adding visual information might indirectly also help to infuse these recording locations with a sense of character; for while this is rarely made explicit (a short note about 'illustrious acoustics' by Norfolk \& Western, quoted in the previous section, notwithstanding), the choice of unusual, non-professional recording locations often also involves a choice to embrace the ambient, acoustic sound qualities of those spaces.

Some albums even indicate specific rooms as recording locations: Pinback's Summer in Abbadon was recorded in 'Absiv's backroom and Rob's bedroom', The Meadowlands by the Wrens 'in our living room on 16-bit ADATs', Roman Candle by Elliott Smith 'on a 4-track in the basement', and M. Ward's Transistor Radio 'in Portland in Mike Coykendall's attic'. By highlighting the fact that albums were recorded in homely, intimate spaces rather than in sterile, professional studios, these liner notes draw attention to the lo-fi character of the recordings. The self-titled album of Kentucky folk-pop band Englishman, described on the band's Bandcamp profile as having come 'into this world imperfect' and endowed with the tag 'bedroom', boasts of an especially unusual and cosy recording location:

Cut to 2-inch tape in a converted barn the band helped to build in rural Ohio, it feels at once familiar and haunted. Ten snowy days of recording were punctuated by family style meals of summer's vegetables and winter's hot toddies. It's likely to be the coziest new album for the coming cold, and any stormy weather thereafter. ${ }^{8}$

This romanticised description of the recording process may call to mind Bon Iver's hunting cabin in Wisconsin. As mentioned at the beginning of this article, the Bon Iver recordings were originally intended as demos for a studio recording, but were upgraded to the status of a 'real' album. This is not an entirely unfamiliar trajectory: a similar origin story is told of Bruce Springsteen's Nebraska, which according to its liner notes was recorded 'on a Teac Tascam Series 144 4-track cassette recorder'. Even more common is the release of home-recorded demos in addition to more polished studio releases, such as Paula Frazer's A Place Where I Know: 4-Track Songs 19922002 or PJ Harvey's 4-Track Demos. Intriguingly, the album Hindu Windmills by Elephant Micah inverses this traditional trajectory, as explained on the album's Bandcamp page:

${ }^{8}$ From https://englishman.bandcamp.com/album/englishman (accessed 31 July 2015). 
I recorded these songs first with Jon Schenke in Evanston, IL. We were working under a lot of time constraints, and when we finished, I felt a need to keep tinkering with the performances and textures that would make up a final version of the album. I put the original sessions aside and began recording at home on a dictaphone, testing out that approach to the material. Meanwhile, the first attempt started showing up on blogs and getting passed around online. For many, this became 'the album.' (...) When my version of the album came out with Time-Lag, some people voiced disappointment in the recording texture. It was difficult for them to conceive of the 'hi fi' recording as a demo of the 'lo fi' official release. ${ }^{9}$

These remarks strike me as interesting for two reasons. First, they demonstrate that recording 'at home' may not only be a matter of intimacy, but also of not being bound by the time pressures involved in studio sessions. Secondly, they show that artists' and listeners' interpretation of the same recording can clash, and that even fans of artists with a solid track-record of lo-fi releases may prefer more polished recordings. Presumably, the listeners who preferred the hi-fi version tend to listen past rather than for the hiss, and the notes act as a friendly reminder that the hiss is there for good; they thus, at least indirectly, serve as an instruction for how to listen to the recordings.

\section{Let me hear the machines grate gears, squeal and grind: materiality and non-transparency}

A common thread running through existing scholarship on lo-fi music - and also on experimental music traditions that work with 'cracked media' or circuit-bending (Kelly 2009; Pinch 2016) - is that it foregrounds the materiality of the recordings and thus rejects the idea of audio transparency. Tony Grajeda, for instance, writes that lo-fi music involves a strategy of 'baring the device' and 'foregrounding its own constructedness' (Grajeda 2003, p. 368). However, I have argued above that the mere presence of recording artefacts such as tape hiss in itself is not enough to 'break the illusion of an unmediated experience with the music' (Dolan 2010, p. 464); after all, music listeners have often practised modes of listening that involve listening past hisses and noises as though they were not there (Sterne 2003; Perlman 2004). Liner notes and other accompanying texts help with emphasising the materiality of the recordings, thus encouraging listeners to listen for, and not past, the hiss.

In fact, several lo-fi releases accomplish this by 'baring the device' in the album title; for instance, the aforementioned compilations of demo recordings by PJ Harvey and Paula Frazer (both featuring 4-tracks), as well as Peter Broderick's 4-Track Songs and Casiotone for the Painfully Alone's Answering Machine Music are named after the recording equipment used on (parts of) the album. Even albums that were mostly recorded in professional settings sometimes nod to the lo-fi equipment used on specific tracks; for instance, several songs on Guided by Voices' 1997 album Mag Earwhig! were recorded 'by Tobin Sprout on his 8-track', while one song on their 2012 album The Bears for Lunch was recorded 'on the boombox'.

Several examples quoted earlier in this paper also contain brief mentions of the equipment used during recording, but some albums give especially detailed explanations. Centro-Matic's The Static vs. the Strings Vol.1, for instance, includes a short description of the circumstances of recording for each song, sometimes including the band's dietary choices or recreational activities, and sometimes listing the exact

\footnotetext{
${ }^{9}$ From http://productofpalmyra.elephantmicah.com/album/hindu-windmills (accessed 31 July 2015).
} 
recording equipment, for instance a 4-tape recorder, 'a PL-20 mic for the drums and a $\$ 1.50$ Sanyo tape recorder microphone for the vocals'. Similarly, Mike Seed's Aether Blues mentions some unusual equipment:

This album is all one take one track straight to minidisc through a lapel microphone held in place by a small safety pin. (...) The [song] title '365 Heavens Descending' refers to Basilides. I wanted it to sound like Brian Jones Presents The Master Musicians of Jajouka so I slapped it onto cassette, put the player in a casserole dish and re-recorded it with the cupboard door shut. It is a tribute to Simon [Pott, who mastered the album] that something listenable cameout [sic] of the cupboard. Mind you, our definition of 'listenable' has always been rather generous. I washed the casserole dish before using it again.

While it is less specific about all the materials used in the recording, the album Secret Soundz by the Pictish Trail uses a noteworthy manner of referring to the recording equipment:

Tracks 3,6 and 9 were recorded by the awesome Tom Knott, at Airtight Studios in Charlton (...) As you can probably tell, all the other songs were recorded by me, at home in Cellardyke, on my ZOOM 8-track thing. [Emphasis added]

Here, the artists make an appeal to the listeners' ability to listen for the hiss and specifically acknowledge their (probable) ability to do so. The Mountain Goats do something similar on their album Full Force Galesburg, where they credit one of their collaborators, Bob Durkee, as having recorded the 'ones that lack wheel-grind'. In doing so, they invite them to use their lo-fi listening skills in order to identify the more lo-fi recordings on the albums, while at the same time also invoking a special bond between performers and listeners as possessing and recognising the value of such a mode of listening.

In the liner notes to All Hail West Texas, the Mountain Goats go even further in highlighting the role of the recording technology in shaping the sonic character of the album. The album, which marked the last of a series of (mostly) home-recorded Mountain Goats albums before moving on to a professional studio environment, was recorded by singer-songwriter John Darnielle, who is also the only performer on the album, on a Panasonic RX-FT500 boombox, whose history is described at length in the liner notes:

Bought at a Circuit City in Montclair, California in 1989 or thereabouts, its functioning used to suggest a combination of two technologies, one brutishly sophisticated and the other magnificently cheap. Its built-in condenser microphone didn't condense (that is, it didn't react to changes in volume by automatically contracting its diaphragm) unless the levels with which it found itself confronted were truly overwhelming, which never happened; meanwhile, oblivious to this tic of mass production, the machine's designers hadn't thought to situate the actual moving parts (that is, the gears) as far as cosmetically possible from this unusually sensitive microphone. The results were uncannily accurate representations of sound complemented and complicated by some pretty ferocious wheel-grind.

This description already hints at questioning the ability of the recording technologies to act as what Jonathan Sterne (2003) refers to as a 'vanishing mediator': rather than simply reproducing the sound of the original performance without adding anything, and thus erasing all traces of the recording technology from the finished product, the Panasonic boombox adds a very distinct sonic quality of its own. The 'ferocious wheel-grind' complicates the idea that a recording can be a neutral document of 
an original performance and acts as a continual reminder to the listeners that the sound emanating from their speakers cannot be thought of as an accurate reproduction of the original audio-signal. In effect, it undermines the illusion of a transparent recording.

Of course, the fact that an old boombox does not allow the production of a transparent recording says little about the theoretical possibility of transparency. However, towards the end of the liner notes, it becomes clear that the Mountain Goats not only describe the aesthetics of these specific recordings, but also question the philosophical possibility of any audio recording to be transparent, no matter how professionally it may be produced or how polished it may sound - and what's more, they suggest that their listeners share this stance: 'Of course the original signal is never actually anywhere near any recordings anywhere, but you already knew that. It is the reason you started reading these lines in the first place.'

In an essay written for a recent reissue of All Hail West Texas, Mountain Goats singer-songwriter John Darnielle complements these meditations on the possibility of sound reproduction with an acknowledgement of their unstable nature. Much to Darnielle's gratification, having declared that the degradation of original sources holds 'dumb romantic appeal' for him, cassettes erode over time. Listeners, he suggests, can compensate for the missing high end 'by humming the root chord; if you can get a friend to do the fifth, so much the better'. The glee taken here in the degradation of recordings fits Grajeda's interpretation of lo-fi as 'the sound of disaffection with a culture evidently impelled toward permanence, purity, perfection' (Grajeda 2003, p. 369).

\section{You can ask the 424 for guidance and for help: agency of technology}

The foregrounding of the materiality of recording technology also raises questions about the status and agency of that technology. While recording technologies are mentioned in the liner notes of many lo-fi releases, the manner in which this happens usually downplays the importance of engineering knowledge and suggests that no specific skill is needed for recording - note, for instance, the acknowledgements in Adem's Homesongs, which thank friends and family for their 'ears, ideas, support and stereos (and pressing " $R$ ")'. This downplaying of engineering knowledge is similar to how circuit-benders often conceptualise the nature of their tinkering with electrical circuits (Pinch 2016). At the same time, the emphasis on incompetence expresses an 'ambivalent attitude to technology' (Bannister 2006, p. 111) and links the recording aesthetics of lo-fi with its penchant for an amateur style of playing, which have been identified as characteristic for lo-fi (Grajeda 2003) and indie rock more generally (Bannister 2006).

Additionally, lo-fi liner notes can raise questions about what counts as 'technology' in the first place. When Mike Seed mentions the role of safety pins and casserole dishes - not exactly the first things to come to mind as music recording technologies - in recording Aether Blues (see previous section), such questions are implicitly put on the table. What is at stake, too, is the boundary between machines, instruments and performers. This boundary has never been exactly clear-cut, as the introduction of new musical instruments, especially mechanical or electronic ones, has often gone hand in hand with a contestation of the boundaries between instruments and machines, and with it, the nature of musical skill and creativity (Pinch 
and Bijsterveld 2003; Pinch and Trocco 2002). The early history of the phonograph also shows some ambiguity about whether the new device should be regarded as a 'talking machine', a musical instrument or even a 'musical performer' (Siefert 1995, p. 443).

To the extent that lo-fi aesthetics emphasise the role of technology, they also grant it a certain amount of agency in shaping the recorded output - whether that is by influencing the length of a song by letting it end when the tape runs out, or by adding a sonic character of its own, e.g. in the form of tape hiss or wheel-grind. In doing so, the recording technology stops being a mere machine and instead becomes a musical instrument - or even a musical performer. The liner notes to the reissue of the Mountain Goats' All Hail West Texas (see previous section) insinuate an equation between human performers and recording technology by suggesting that a human performer could compensate for a degraded recording, but the original liner notes of the same album go even further in suggesting that the recording technology itself acts as a performer:

It is a painfully raw sound that can legitimately be thought of as a second performer on these otherwise unaccompanied recordings. (...) Some of us, when we're really sleepy or facing an unacceptable loss, imagine the hand of a person behind all this: an ornery little fellow who will have no sound without a second sound to obscure and pollute it, who is deeply mistrusting of singers in general, and who believes that whatever 'signal-to-noise' ratio might mean, it can't be any good unless more value is placed on the latter of the two hyphenated terms.

Here, the Panasonic is not just credited as a second instrument next to the guitar, but as a second performer next to John Darnielle. Indeed, the image of an 'ornery little fellow' even attributes it with a sense of personality and agency, and a desire to undermine the authority of human performers and to destroy the illusion of recording transparency. This anthropomorphisation of machines is similar to musicians' preference for analogue synthesisers because they dislike the uniformity and predictability of digital instruments and are drawn to the imperfections and idiosyncrasies of the analogue devices, which they think of as 'a living-breathing entity that you can interact with and even fall in love with' (Pinch and Trocco 2002, p. 319). By favouring the unpredictability of technology, some of the responsibility for the resulting sound is delegated to the instrument or recording technology; and by making this explicit to the listeners, the mediated nature of the recordings is highlighted.

\section{Conclusion}

In this paper, I have demonstrated that many lo-fi musicians use liner notes to provide their listeners with a frame of reference that invites them to interpret their music as lo-fi. Indeed, contrary to some definitions that emphasise the audibility of tape hiss, static or wheel-grind as characteristics of lo-fi, I argue that their mere presence is not enough: over more than a century since the advent of audio recording technologies, music listeners have honed their skills in listening past such recording artefacts (Sterne 2003; Perlman 2004). Musical recordings become lo-fi not if they contain imperfections and artefacts, but rather if these are noticed by listeners as an integral part of the music. As I have shown, artists use particular curatorial practices to help listeners interpret the recordings in such a lo-fi manner and to adopt a listening mode that listens for rather than past the hiss. 
In analysing how liner notes cultivate a lo-fi mode of listening, I have identified several tropes running through the discourse of lo-fi music: the avoidance of state-of-the art recording technology and professional production techniques in the name of authenticity, honesty and spontaneity; the creation of site-specificity and intimacy through an emphasis on home-recording; the foregrounding of the materiality of the recording technology, which undermines the idea of audio transparency; and finally, the question of the recording technology's agency as it straddles the boundary between machine, musical instrument and performer. These tropes, taken together, help to make sense of how genre-adequate modes of listening are constructed in lo-fi music. This analysis opens up two trajectories for further research: towards a better understanding of lo-fi music, and towards a better understanding of liner notes as a format.

For a better understanding of lo-fi, it would be interesting to consider what is left unsaid in liner notes. My analysis has pointed at many instances where liner notes highlight elements that are added to the music as a result of lo-fi recording approaches, such as tape hiss, wheel-grind or static, or mistakes that - unlike in hi-fi recordings - were not removed. Much less emphasis seems to be placed on what is 'subtracted': while a reduced frequency range is arguably just as characteristic of lo-fi recordings as tape hiss is, it is not usually made explicit in liner notes, although technically versed listeners may be able to infer it from mentions of the recording equipment. (The Mountain Goats' celebration, in the reissue of All Hail West Texas, of the degradation of recordings over time is a notable exception, which does draw attention to what was lost in the process.)

Additionally, it could be fruitful to investigate albums which are widely considered to be canonical examples of lo-fi music, but which do not feature liner notes that invite their listeners to consider them as such. Such albums undeniably exist, but have been outside of the purview of the current article, which was concerned with how liner notes help to situate a particular recording within the universe of lo-fi in the first place, and therefore focused only on albums that made such an effort. However, some of the albums that I returned to my own or friends' shelves without finding any relevant liner notes did make me ponder - why, for instance, do the Guided by Voices albums Bee Thousand and Alien Lanes, widely considered as key examples of lo-fi at the height of its popularity (Encarnacao 2013), not inform listeners of their home-recorded nature, while some of their later, mostly studio-recorded albums draw attention to the few songs that were recorded on non-professional equipment? ${ }^{10}$ And why did the Mountain Goats dedicate a whole essay to their trusty boombox just before starting to consistently record their albums in professional studios? A detailed study of how liner notes about lo-fi listening feature in the career trajectories of particular bands could certainly be a worthwhile undertaking.

And if albums can be considered lo-fi although their liner notes make no effort to stage them as such, that raises the question of the existence of other practices that highlight the lo-fi character of recordings, and their interactions with liner notes. And what does applying a lo-fi mode of listening mean in practice, anyway? My analysis here was concerned with the ideal modes of listening constructed in lo-fi discourse,

10 To further complicate this narrative, it should be noted that the album released just before Bee Thousand and Alien Lanes, Vampire on Titus, does highlight the non-professional recording circumstances ('rec. at Steve's 8-track and Tobe's 4-track'). 
rather than the actual listening practices of those who listen to lo-fi music - but as such, it could provide the basis for an ethnographic exploration of how such modes of listening are accomplished in practice.

In relation to a more general understanding of the functions and uses of liner notes, the research presented here could inspire studies of how liner notes in other musical genres may display similar curatorial practices and invocations of modes of listening - even if those modes of listening themselves may differ considerably from those of lo-fi music. To the extent that liner notes function as curatorial practices to give a frame of reference to recordings, the spread of digital formats such as mp3s provides a challenge for artists, who can be less confident than ever that listeners will hold the physical album sleeve in their hands while listening to a musical recording. Certainly, that does not mean that artists have no way of giving a frame of reference for their recordings, as for instance the practice of including notes on digital platforms like Bandcamp.com shows. Nor does it mean that listeners cannot access the liner notes contained in the physical releases, as they may be able to do so digitally. However, the status of liner notes as a format is certainly undergoing changes which makes a thorough understanding of what liner notes actually do even more pertinent for scholars of popular music.

\section{Acknowledgements}

I would like to express my gratitude to Ulrike Felt (for her support with a very early version of this paper, which I wrote for her class in the sociology of technology at the University of Vienna), Joseph $\mathrm{O}^{\prime}$ Connell (for thinking along with me about this paper for many years and for suggesting the term 'curatorial' in relation to my argument), Jean-Yves Bart and Maria Hüren (for allowing me to peruse their record collections while collecting the material for this paper and discussing my findings with me). I am also grateful for the suggestions of Maarten Michielse and my colleagues in the MUSTS research programme, for the comments I received when presenting this material at the ARP and STS conferences, and for the very helpful suggestions of the journal editors and two anonymous peer reviewers.

\section{References}

Adorno, T.W. 1976 [1962]. 'Types of musical conduct', in Introduction to Music Sociology (New York, Seabury Press), pp. 1-20

Bannister, M. 2006. White Boys, White Noise: Masculinities and 1980s Indie Guitar Rock (Aldershot, Ashgate)

Barry, E. 2015. 'Mono in the stereo age', in Living Stereo: Histories and Cultures of Multichannel Sound, ed. P. Théberge, K. Devine and T. Everrett (New York, Bloomsbury), pp. 125-46

Bennett, A. 2002. 'Music, media and urban mythscapes: a study of the "Canterbury Sound"', Media, Culture $\mathcal{E}$ Society, 24/1, pp. 87-100.

Biron, D.L. 2011. 'Writing and music: album liner notes', Portal: Journal of Multidisciplinary International Studies, 8/1, http://dx.doi.org/10.5130/portal.v8i1.1682 (accessed 15 January 2016)

Bottomley, A.J. 2016. 'Play it again: rock music reissues and the production of the past for the present', Popular Music and Society, 39/2, pp. 151-74

Campopiano, J. 2014. 'Memory, temporality, \& manifestations of our tech-nostalgia', Preservation, Digital Technology \& Culture, 43/3, pp. 75-85

Demers, J. 2010. Listening Through the Noise: The Aesthetics of Experimental Electronic Music (Oxford, Oxford University Press)

Devine, K. 2013. 'Imperfect sound forever: Loudness wars, listening formations and the history of sound reproduction', Popular Music, 32/2, pp. 159-76 
Dolan, E.I. 2010. '“. . This little ukulele tells the truth": indie pop and kitsch authenticity', Popular Music, 29/3, pp. 457-69

Eells, J. 2011. 'The solitary fame of Bon Iver's Justin Vernon', Rolling Stone, http://www.rollingstone.com/music/ news/the-solitary-fame-of-bon-ivers-justin-vernon-20110623 (accessed 29 July 2015)

Eley, C. 2011. 'Technostalgia and the resurgence of cassette culture', in The Politics of Post-9/11 Music: Sound, Trauma, and the Music Industry in the Time of Terror, ed. J.P. Fisher and B. Flota (Farnham, Ashgate), pp. 43-54

Encarnacao, J. 2013. Punk Aesthetics and New Folk: Way Down the Old Plank Road (Farnham, Ashgate)

Gracyk, T. 1996. Rhythm and Noise: An Aesthetics of Rock (London, I.B. Tauris)

Grajeda, T. 2003. 'The sound of disaffection', in Hop on Pop: The Politics and Pleasures of Popular Culture, ed. H. Jenkins, J. Shattuc and T. McPherson (Durham, NC, Duke University Press), pp. 357-75

Hibbett, R. 2005. 'What is indie rock?', Popular Music and Society, 28/1, pp. 55-77

Kelly, C. 2009. Cracked Media: The Sound of Malfunction (Cambridge, MA, The MIT Press)

Kromhout, M.J. 2012. 'As distant and close as can be. Lo-fi recording: site-specificity and (in)authenticity', Soundscapes 15, http://www.icce.rug.nl/ soundscapes/VOLUME15/Lo-fi.shtml (accessed 17 July 2015)

Leonard, M. 2014. 'Staging the Beatles: ephemerality, materiality and the production of authenticity in the museum', International Journal of Heritage Studies, 20/4, pp. 357-75

Matula, T. 2007. 'Pow! to the people: the Make-Up's reorganization of punk rhetoric', Popular Music and Society, 30/1, pp. 19-38

Milner, G. 2009. Perfecting Sound Forever (London, Granta)

Morton, D. 2000. Off the Record: The Technology and Culture of Sound Recording in America (New Brunswick, NJ, Rutgers University Press)

Perlman, M. 2004. 'Golden ears and meter readers: the contest for epistemic authority in audiophilia', Social Studies of Science, 34/5, pp. 783-807

Peterson, R.A. 1997. Creating Country Music: Fabricating Authenticity (Chicago, IL, The University of Chicago Press)

Pinch, T. (2016). "“Bring on sector two!” The sounds of bent and broken circuits', Sound Studies, 2/1, pp. 36-51

Pinch, T.J., and Bijsterveld, K. 2003. "'Should one applaud?" Breaches and boundaries in the reception of new technology in music', Technology \& Culture, 44/3, pp. 536-59

Pinch, T., and Bijsterveld, K. 2004. 'Sound studies: new technologies and music', Social Studies of Science, 34/5, pp. 635-47

Pinch, T., and Reinecke, D. 2009. 'Technostalgia: how old gear lives on in new music', in Sonic Souvenirs: Audio Technologies, Memory and Cultural Practices, ed. J. Van Dijck and K. Bijsterveld (Amsterdam, Amsterdam University Press), pp. 152-66

Pinch, T., and Trocco, F. 2002. Analog Days: The Invention and Impact of the Moog Synthesizer (Cambridge, MA, Harvard University Press)

Plourde, L. 2008. 'Disciplined listening in Tokyo: onkyo and non-intentional sounds', Ethnomusicology, 52/2, pp. 270-95

Schilt, K. 2003. "“A little too ironic": the appropriation and packaging of Riot Grrrl politics by mainstream female musicians', Popular Music and Society, 26/1, pp. 5-16

Siefert, M. 1995. 'Aesthetics, technology, and the capitalization of culture: how the talking machine became a musical instrument', Science in Context, 8/2, pp. 417-49

Solomon, T. 2005. "'Living underground is tough": authenticity and locality in the hip-hop community in Istanbul, Turkey', Popular Music, 24/1, pp. 1-20

Sterne, J. 2003. The Audible Past: Cultural Origins of Sound Reproduction (Durham, NC, Duke University Press)

Sterne, J. 2006. 'The MP3 as cultural artifact', New Media E Society, 8/5, pp. 825-42

Stockfelt, O. 1997. 'Adequate modes of listening', in Keeping Score: Music, Disciplinarity, Culture, ed. D. Schwarz, A. Kassabian and L. Siegel (Charlottesville, VA, University Press of Virginia), pp. 129-46

Supper, A., and Bijsterveld, K. 2015. 'Sounds convincing: modes of listening and sonic skills in knowledge making', Interdisciplinary Science Reviews, 40/2, pp. 124-43

Théberge, P., Devine, K., and Everrett, T. 2015. Living Stereo: Histories and Cultures of Multichannel Sound (New York, Bloomsbury)

Thompson, E. 1995. 'Machines, music, and the quest for fidelity: marketing the Edison phonograph in America, 1877-1925', The Musical Quarterly, 79/1, pp. 131-71

Williams, J.P. 2006. 'Authentic identities: straightedge subculture, music, and the internet', Journal of Contemporary Ethnography, 35/2, pp. 173-200

Wright, A. N. 2013. 'Exploring the funkadelic aesthetic: intertextuality and cosmic philosophizing in funkadelic's album covers and liner notes', American Studies, 52/4, pp. 141-69

\section{Discography}

Adem, Homesongs. Domino, WIGCD129. 2004

Beatnik Filmstars, In Great Shape. Track \& Field, Heat 40. 2006 
Beatnik Filmstars, Shenaniganism (Tape Hiss \& Other Imperfections). The International Lo-Fi Underground, WOOF4. 2007

Beltline, These Things You Do At Four A.M. Jealous Butcher, JB-028. 2001

Bon Iver, For Emma, Forever Ago. Jagjaguwar, JAG115. 2008

Peter Broderick, Home. Bella Union, BELLACD172. 2008

Peter Broderick, 4-Track Songs. Type, TYPE044. 2009

Casiotone for the Painfully Alone, Answering Machine Music. Tomlab, tom 21. 2003

Centro-Matic, The Static vs. the Strings Vol. 1. Idol, IR035. 2002

Colin Clary, Sweater Weather or Not, These Are the Songs I Got. Asaurus, ASA043. 2005

Elephant Micah, Hindu Windmills. Time-Lag, \#35. 2007

Englishman, Englishman. Self-released/Cave City Music, no catalogue number. 2010

Paula Frazer, A Place Where I Know: 4-Track Songs 1992-2002. Fargo, FA20391. 2003

Guided by Voices, Vampire on Titus. Scat, scat31, 1993

Guided by Voices, Bee Thousand. Scat, scat35, 1994

Guided by Voices, Alien Lanes. Matador, OLE 123-2. 1995

Guided by Voices, Mag Earwhig! Matador, OLE 241-2. 1997

Guided by Voices, The Bears for Lunch. Fire, FIRECD259, 2012

PJ Harvey, 4-Track Demos. Island, 314-518 450-2. 1993

Iron \& Wine, The Creek Drank the Cradle. Sub Pop, SPCD 600. 2002

Jack Logan, Bulk. Medium Cool-Twin/Tone, MCR 89261-2. 1994

The Make-Up, Destination: Love; Live! At Rice. Dischord, DIS99 V. 1996

The Mountain Goats, Full Force Galesburg. Emperor Jones, EJ-11LP. 1997

The Mountain Goats, All Hail West Texas. Emperor Jones, EJ-41CD. 2002; re-released with additional liner notes and bonus tracks: Merge, MRG481. 2013

Norfolk \& Western, Winter Farewell. FILMguerrero, Fg09. 2002

The Pictish Trail, Secret Soundz, Fence, FNC904. 2008

Pinback, Summer in Abbadon. Touch and Go, TG237CD. 2004

Mike Seed, Aether Blues. SVC, SVC 16. 2008

Elliott Smith, Roman Candle. Domino, REWIGCD. 1998

Rob Snarski, Low Fidelity: Songs by Request vol. 1. Teardrop, TRP702. 2015

Sodastream, Reservations. Hausmusik, HM073. 2006

Spokane, The Proud Graduates. Jagjaguwar, JAG35. 2001

Bruce Springsteen, Nebraska. Columbia, COL 511303 2. 1982

Sufjan Stevens, Greetings From Michigan: The Great Lake State. Rough Trade, RTRACD170. 2003

Kevin Tihista, Home Demons Volume 1. Broken Horse, BKH-CD008. 2005

M. Ward, Transistor Radio. Matador, OLE 642-2. 2005

Paul Westerberg/Grandpaboy, Stereo/Mono. Vagrant, VR369. 2002

The Wrens, The Meadowlands. Absolutely Kosher/BB*Island, AK 009/bbi0031. 2006 